\title{
The Analysis of the Impact of Master Station's Performance and Mechanism on the Success Rate of Electricity Usage Information Collection
}

\author{
Shuang Gao ${ }^{1, a^{*}}$, Gangjun Gong ${ }^{2, b}$, Baogang Zhang ${ }^{3, c}$ and Wanqing Yang ${ }^{4, d}$ \\ ${ }^{1}$ Beijing Engineering Research Center of Energy Electric Power Information Security (North China \\ Electric Power University), No.2, Beinong Road, Huilongguan Town, Changping District, Beijing, \\ China
}

${ }^{2}$ Beijing Engineering Research Center of Energy Electric Power Information Security (North China Electric Power University), No.2, Beinong Road, Huilongguan Town, Changping District, Beijing, China

${ }^{3}$ Information \& Telecommunication Branch

Of State Grid Dalian Electric Power Supply Company, Xigang District, Dalian, China

${ }^{4}$ Information \& Telecommunication Branch

Of State Grid Dalian Electric Power Supply Company, Xigang District, Dalian, China

agaoshuang19930514@163.com, bgonggangjun@126.com, 'zhangbaogang@126.com, dyangwanqing@126.com

\begin{abstract}
Keywords: Electricity usage information collection system; master station's performance; called measuring mechanism; success rate of collection
\end{abstract}

\begin{abstract}
Electricity usage information collection system includes a master station system, communication channel and terminal devices. Among them, the master station system is the brain center of electricity information collection system which can achieve called measuring mechanism storage, calculation and analysis, data exchange, time calibration, file management. The advantages and disadvantages of master station's performance, and rationality of handling mechanism directly affect the normal operation of the electricity information collection system. Therefore, based on various types of data extracted from the master station, this paper analyzes the impact on the success rate of information collection from perspectives of master station's performance, communication concurrent, called measuring mechanism, time calibration mechanism, records management, online statistics and operational stability.
\end{abstract}

\section{Introduction}

Electricity information collection system is an information collection, processing, and real-time monitoring system, it includes a master station system, a communication channel and a terminal equipment. Master station system as the central system of electricity information collection system, its design mechanism and operation state will affect the timeliness, accuracy, completeness of the electricity usage data collection, safety, stableness and efficiency of the collection system. Literature [1] states that errors of terminal parameters in the master station system will cause that the terminal is not online in the master station system interface, leading to the terminal not displaying correctly online. Literature [2] presents when we use GPRS communication module on a real scenario, we often encounter problems, such as it cannot be online, the signal is great but cannot be on line and often drop calls, leading to the situation that the master device cannot communicate properly with the automatic meter reading, thus affecting collection success rate. Literature [3] states that whether data transmitted by terminal is complete or not will impact on the collection work, and the data collected will be uploaded completely only if the master station allocate tasks properly. However, the above document does not have a detailed analysis of their impact on the success rate of collection from the perspective of their own performance and mechanism of the master station. Therefore, based on various types of data extracted from the master station, this paper analyzes the impact on the success 
rate of information collection from perspectives of master station's performance, communication concurrency, called measuring mechanism, time calibration mechanism, records management, online statistics and operational stability.

\section{The composition of electricity usage information collection system}

Electricity information collection system consists of three parts, a master station, a communication channel and collection devices. The composition structure of the system is shown in Fig. 1.

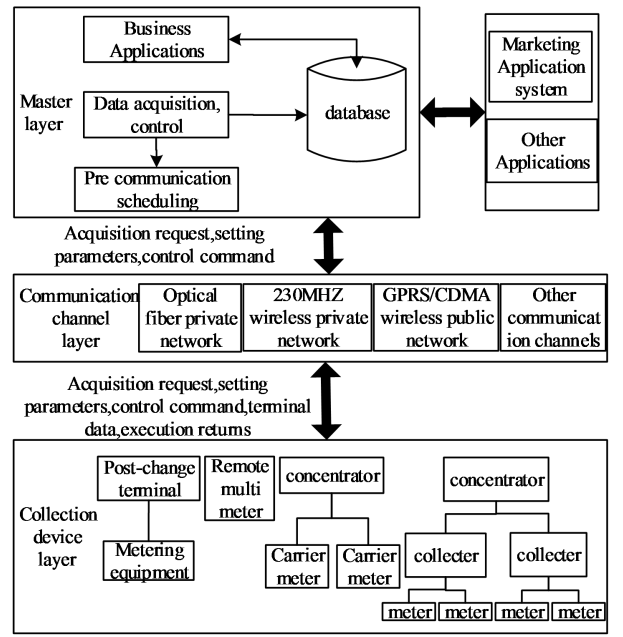

Fig. 1. Electricity information collection system organizational structure

Master station system accomplishes business applications, data collection, execution controlling, pre-communication scheduling, database management and other functions. Collection devices are terminals and metering equipments installed on the scene, responsible for collecting and providing the raw power of the entire system, including special variant collection terminals, concentrators, collectors and smart meter and so on. Communication channel is used for remote data communication between master station and collection terminal, including fiber-optical network, 230MHZ Wireless Network, General Packet Radio Service / code division multiple access (GPRS / CDMA) wireless public network.

The analysis of the performance and mechanism of a master station constraint on the success rate information collection

Based on data extracted from information collection system in a master station of a domestic province from July 1, 2014 to December 31, 2014,this paper analyzes the impact on the success rate of information collection from perspectives of the master station's performance, communication concurrency, called measuring mechanism, time calibration mechanism, records management, online statistics, operational stability.

The analysis of the restraining factors of the master station's performance on the success rate of data collection .

a) Analysis of the influence of the master station's operation stability on the success rate of data collection.

The success rate of data collection is influenced by the failure of the master station hardware equipment (mainly front machine and database failure), for example, in October 1, 2014, front server malfunction caused that province's success rate of data collection dropped to $87 \%$ or so; in November $22,23,19,2014$, database server failure caused that the province's success rate of data collection dropped to $92 \%$ or so. There are many cases such as database failure, front server failure that can cause the dropdown of success rate of collection. The condition that the operation and maintenance of master station hardware devices have no clear management unit results in that the provincial measurement center cannot accurately grasp the operating conditions of master station. The dropdown of success rate of collection tells us that there are some problems with hardware of the master station; these problems seriously affect collection management and controlling of timeliness. 
Therefore, perfecting the project needs to rely on the expansion and performance improvement of the master station in the electricity usage information collection system, and the existing performance index that does not satisfy the actual demand needs to be upgraded comprehensively in the master station, and the main objectives include reducing the pressure of the production database, improving the response speed of WEB pages, meeting the requirements of timeliness of statistical analysis of business applications, and regulating the external interface. Realizing the smooth transition of structure adjustment and performance optimization of the collection system to ensure the stability and reliability, and using distributed cloud computing technology, memory storage technology, data partition technology, production and application of separation technology and other emerging technologies to solve the problem of system construction and function.

b) The analysis of the influence of master station's operation and maintenance management on the success rate of collection.

The proper running of hardware has a greater impact on the operation of electricity usage information collection system, and it requires high demand of profession. The province metrological center still does not have enough hardware equipment operation and maintenance personnel, and provincial ICT company in communication technology and the hardware equipment operation and maintenance are more professional than the province metrological center, it is recommended that the provincial ICT company is responsible for the master station's maintenance according to "information collection system operation and maintenance management approach" of State Grid.

c) The analysis of the impact of the master station's data processing power on the success rate of data collection.

According to the State Grid No. 153 regulation, it is a large scale information collection system when the number of users is within 5-10 millions, currently, the vast majority of domestic provinces belong to the class of large scale information collection system. At the same time, with the number of access users increasing and with the in-depth development of collection business, electricity usage information collection system needs more types of data, higher frequency and larger number of data, all of which form a large quantity of data. In 0 o'clock or so which usually has more pressure than other time in a day, there are millions of records need to be parsed and saved to the database, excluding the alarm and heartbeat packets, processing requirements of the time is about tens of millions per second. The high concurrency of the environment and the vast amount of data put a big pressure on the system's reliability and availability. Therefore, the processing of the vast amount of data through the master station and the front machine, and the uplink processing of high concurrent automatic tasks constraint efficiency of communication.

The analysis of the constraint factors on the success rate of collection in the field of master station's mechanism strategy

a) The analysis of the impact of the main station call on communication.

The "power user information collection system design guide" released by State Grid Corporation specifies the detailed requirements of methods to collect terminal device, that is, the master station of information collection is a background management software which is in charge of controlling and management of information collection device, and is mainly responsible for the command release, data collection, data receiving, data processing, data storage on hardware of collection system, and is responsible for providing raw data to other management systems. The master station acquisition system can collect all types of electricity customers and each monitoring point, in conformity with the standards of the State Grid Corporation, covering smart ammeter, ordinary 485 electronic ammeter, collect data remotely and control pre-pay for residential users, collect and monitor data timely as well as remotely for electric source and other metering point. Collecting data types contain all types of data required for the management, the primary collection methods are automatic and time-specified collection, testing data randomly, reporting data actively, the specific implementation is shown in Table 1: 
Table 1 Master station collection mode

\begin{tabular}{|c|c|c|}
\hline $\begin{array}{c}\text { Master station collection } \\
\text { mode }\end{array}$ & Specific implementations & Master station function \\
\hline $\begin{array}{c}\text { Automatic and } \\
\text { time-specified collection }\end{array}$ & Set time interval, automatically collect data & $\begin{array}{c}\text { Automatic and manual } \\
\text { collection function }\end{array}$ \\
\hline Testing data randomly & Real time manual testing data & $\begin{array}{c}\text { Data collection and } \\
\text { processing }\end{array}$ \\
\hline Reporting data actively
\end{tabular}

At present, there are three problems in the data timing called measured of the master station, as shown in Table 2:

Table 2 Problems in testing data of master station regularly

\begin{tabular}{|c|c|c|}
\hline $\begin{array}{c}\text { Existing problems } \\
\begin{array}{c}\text { Master station's } \\
\text { imperfect }\end{array}\end{array}$ & $\begin{array}{c}\text { Raster station do not check whether the } \\
\text { operation of freezing data daily is successful or } \\
\text { not }\end{array}$ & $\begin{array}{c}\text { Waste a large amount of } \\
\text { communication channel resources }\end{array}$ \\
\hline $\begin{array}{c}\text { Artificial collecting } \\
\text { is not timely }\end{array}$ & $\begin{array}{c}\text { Complementary test is created manually } \\
\text { weekends are not enough, collecting } \\
\text { task is not timely }\end{array}$ \\
\hline $\begin{array}{c}\text { Special variable } \\
\text { sampling strategy is not } \\
\text { appropriate }\end{array}$ & $\begin{array}{c}\text { Master station do not check if the data } \\
\text { collected before current time is successful or not } \\
\text { when collect special transformer }\end{array}$ & $\begin{array}{c}\text { The data packet is so long that } \\
\text { the copy fails between 23:00 and } \\
0: 00\end{array}$ \\
\hline b) The analysis of the influence of the master station's time calibration mechanism on
\end{tabular}
communication.

Designing guidelines of the power user electric energy data collection system released by the State Grid Corporation put forwards requirements for the methods of time calibration of information collection system terminal device, as follows:

- The system has standard time calibration function, and standard time can be obtained from other systems.

- The master station in the system can do broadcast time calibration or patch time calibration for all terminal device, can also do time calibration for a single terminal.

- The master station can perform remote calibration of ammeter which has deviation $<5 \mathrm{~min}$ from current time.

There are many abnormal situations of terminal devices and ammeter's clock when we do time calibration in a province, and the success rate of data acquisition is affected by the abnormal of the clock, among them, it is the problem of quality of battery when terminal clock's deviation is over 24 hours, however, there are more cases that ammeters and terminals' timeout is more than 5 minutes, and the cause is communication failure during calibration.

Among them, for example, in December 24, 2014, within a province, there are 590 terminals which the timeout is over 24 hours compared with master station, 558 terminals within 1-24 hours, 23380 terminals within 15-60 minutes, 23751 terminals within 15 minutes, and 3715 terminals within 1-5 minutes. The statistics is shown in Fig 2:

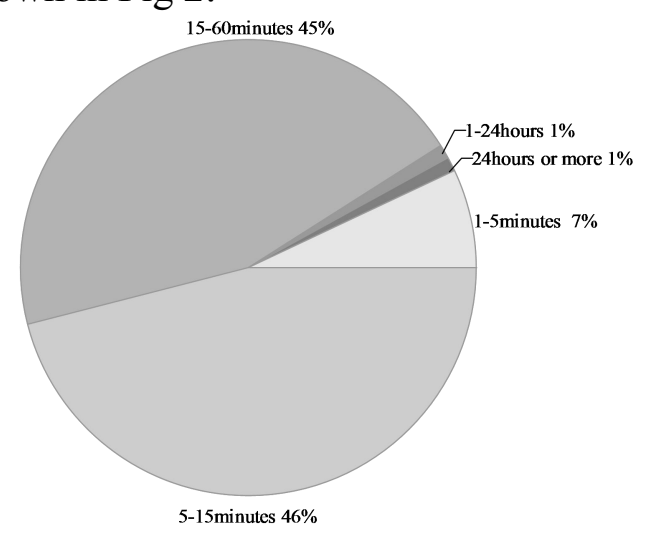

Fig. 2. Terminal clock abnormal situation statistics 
Specific Reason Analysis: Standard issued by the State Grid Corporation QGD/W 37.61 provisions "communication protocol can include time tag", therefore, the electricity information collection system has time tag when sends messages, if the deviation between terminal and system clock is so wide that it may lead to the timeout of terminal's judgment which can make the terminal lose the ability to accept master station's data and resulting in communication failure.

c) The analysis on the influence of master station's archives management on communication.

Master station's file management focuses on maintaining grid structure, users, collection points, equipment which are all important parts of system operation, realizing the object of file management and patch import timely from marketing to other system, in order to maintain the consistency and accuracy of archives information. In this paper, we make a full analysis of one of Chinese provinces' master station's file management, check the old files and modified files during the maintenance of devices and find that the inconsistency of files between data files and work files in information collection system, do not achieve consistency and synchronization of system station's file management, and archival data of the electric energy meter, collector, concentrator, negative control terminal in the work scene are not consistent with master station' s file, all of which have impact on the operation of system communication channel, as specified in Table 3 shows:

Table 3 Factors of the master station archives management on communication

\begin{tabular}{|c|c|}
\hline Influential factors & Specific performance \\
\hline User Profile & $\begin{array}{c}\text { collection system files and system files are not } \\
\text { synchronized with marketing SG186 }\end{array}$ \\
\hline Collection Equipment Archives & Imperfect collection device file \\
\hline Missing SIM card information & $\begin{array}{l}\text { Unable to access wireless public network, not } \\
\text { convenient for operation and maintenance }\end{array}$ \\
\hline
\end{tabular}

d) The analysis of the influence of the master station's online statistics rate on communication.

In the master station of a province we extract the success rate of collection, the number of terminals and the number of online terminal from 2014 July 1, 2014, December 1, and 2015 February 1 , and we find that the rate of online terminal is generally higher than the success rate of collection of terminal, as is shown in the following chart (Table 4). After analysis of this behavior, it is found that the integrated master station collect the rate of online terminals on a daily basis, so the rate of online terminal is generally higher than the success rate of collection of terminal, and we should include the frequency of statistics on the rate of online terminals.

Table 4 The influence of statistics frequency on the success rate of the collection of electricity

\begin{tabular}{|c|c|c|c|}
\hline Time & 2014.7 & 2014.12 .1 & 2015.2 .1 \\
\hline Data & 119601 & 155930 & 165312 \\
\hline Number of concentrators & 118142 & 155460 & 164670 \\
\hline Number of concentrators line terminal & 641654 & 722585 & 729457 \\
\hline Collector number & 9057595 & 11817358 & 12763325 \\
\hline Meter number & 9011900 & 11767472 & 12711819 \\
\hline Meter online & $97.85 \%$ & $98.37 \%$ & $97.98 \%$ \\
\hline Online success rate & $97.25 \%$ & $97.96 \%$ & $97.58 \%$ \\
\hline Collection success rate & \multicolumn{2}{|l}{}
\end{tabular}

\section{Summary}

The success rate of electricity information data collection directly affects that whether the smart grid "big marketing" system can meet the demand of deepening business applications by "SG186" system or not, whether it can effectively support the development of new energy resources, the execution of carrying out the multi-level electricity price, and the development of two-way interactive services. Therefore, based on a currently running master station system in one of our country's provinces, by sampling extraction of data, this paper focuses on the analysis of the impact of master station's performance and mechanism of electricity usage information collection system on the success rate of collection, in order to provide certain reference to achieve "full coverage, full collection, full cost controlling" of electricity usage information collection. 


\section{Acknowledgment}

The work was supported by a general program from the Basic Science Research Fund of Central Universities (No.JB2014048).

\section{References}

[1] Jiangyi Hu, Enguo Zhu, Xingang Du et al. Application status and development trend of electric information acquisition system [J]. power system automation, 2014, DOI:10.7500/AEPS20130617005. 131-135.

[2] Zhenrong Kuang Electricity information collection system master collection platform design and implementation of [D]. University of Electronic Science and Technology, 2011.

[3] Xiang Lu. Analysis of factors affecting the success rate of electric information acquisition and processing measures $[\mathrm{J}]$. modern manufacturing, 2013, (27): DOI:10.3969/j.issn.1671-0797.2013.27.005. 8-9.

[4] Lei Liu. Research on the application of low voltage customer power information acquisition system [D]. Shandong University, 2012 DOI:10.7666/d.y2183966.

[5] Xiaodi YuWen. Power user electric energy data acquire system research and application [D]. North China Electric Power University (Beijing), 2011. DOI:10.7666/d.y1954056.

[6] Hailong Mu, Jingbo Li. Analysis of the success rate of the impact of the use of electric information acquisition of $[\mathrm{J}]$. power demand side management, 2011, 13 (6): DOI:10.3969/j.issn.1009-1831.2011.06.017. 60-62.

[7] Xiaofang Yang. Analysis of the success rate of the impact of the use of electricity information collection [J]. China Electric Power Education, 2014, (33).

[8] Junhua Guo, Chunyan Zhang. Analysis and countermeasure research on the acquisition rate of power information acquisition system [J]. science and technology innovation and application, 2014, (24): 176-176. 